\title{
Which came first: validity or clinical testing? The example of long QT genes
}

\author{
Lacey Boshe ${ }^{1}$, A. Katherine M. Foreman², Jennifer L. Goldstein², Natasha T. Strande ${ }^{3}$, Jonathan S. Berg ${ }^{2}$, \\ Julianne M. O'Daniel² \\ 1School of Medicine, University of North Carolina, Chapel Hill, NC 27516, USA. \\ 2Department of Genetics, University of North Carolina, Chapel Hill, NC 27516, USA. \\ ${ }^{3}$ Department of Pathology and Laboratory Medicine, University of North Carolina, Chapel Hill, NC 27516, USA.
}

Correspondence to: Prof. Julianne M. O'Daniel, Department of Genetics, University of North Carolina, Campus Box \# 7264, Chapel Hill, NC 27599, USA. E-mail: jodaniel@med.unc.edu

How to cite this article: Boshe L, Foreman AKM, Goldstein JL, Strande NT, Berg JS, O'Daniel JM. Which came first: validity or clinical testing? The example of long QT genes. J Trans/Genet Genom 2018;2:12. https://doi.org/10.20517/jtgg.2018.18

Received: 1 Jul 2018 First Decision: 4 Jul 2018 Revised: 17 Aug 2018 Accepted: 17 Aug 2018 Published: 30 Aug 2018

Science Editor: Sheng-Ying Qin Copy Editor: Cai-Hong Wang Production Editor: Huan-Liang Wu

\begin{abstract}
Aim: To investigate the potential relationship between the strength of evidence for a gene-disease association and inclusion of the gene on a targeted, indication-based gene panel test for hereditary long QT syndrome (LQTS) and to explore factors that may influence laboratory decisions about the inclusion or exclusion of genes from these clinical tests.
\end{abstract}

Methods: A comprehensive literature search was performed to quantify existing evidence supporting putative LQTS gene-disease associations. This evidence included the year that the gene was first implicated in LQTS, the total number of published cases of LQTS attributed to the gene, and the presence of published segregation and functional data for the gene. To explore the possible relationship between the published evidence for clinical validity of each gene and availability of clinical genetic testing, semi-structured interviews were conducted with key laboratory stakeholders. Representatives from nine US laboratories offering clinical LQTS gene testing agreed to be interviewed regarding decision-making about when and why genes comprising their clinical LQTS test offerings were added.

Results: Genes associated with LQTS before 2006 generally had more reported cases of LQTS and the greatest amount of supporting segregation and functional data prior to being offered as a clinical test. For genes first linked to LQTS after 2006, these trends are less linear and the timeframe between initial report and inclusion on clinical test menus decreased substantially. Advances in technology, lifting of patents, clinician request, and literature searches were cited as the main factors that influence composition of LQTS gene panel tests. Paradoxically, one lab director noted that it may require more evidence to remove a gene than to add a gene to a clinical test panel.

Conclusion: Our evaluation of the LQTS genes illustrates the nuanced relationship between published evidence supporting a gene-disease association and availability of clinical testing. Expert assessment of clinical validity of gene-

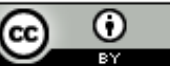

(C) The Author(s) 2018. Open Access This article is licensed under a Creative Commons Attribution 4.0 International License (https://creativecommons.org/licenses/by/4.0/), which permits unrestricted use, sharing, adaptation, distribution and reproduction in any medium or format, for any purpose, even commercially, as long as you give appropriate credit to the original author(s) and the source, provide a link to the Creative Commons license, and indicate if changes were made.

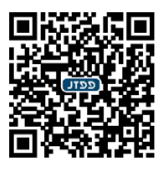


disease associations may help laboratories to determine gene panel content. The ultimate impact of such information on the composition of clinical gene tests as well as their utilization by clinicians and coverage by health insurance policies remains to be seen.

Keywords: Clinical validity, NGS tests, long QT syndrome, gene panels, PanelApp, ClinGen

\section{INTRODUCTION}

Advances in genomic sequencing technology enable laboratories to sequence large numbers of genes from a single sample at a relatively low cost. Massively parallel sequencing based multi-gene tests or "panel tests" have rapidly become a standard offering from clinical diagnostic laboratories. Gene discovery research also benefits from the use of this technology leading to an escalating pace for new gene discovery ${ }^{[1]}$. This may result in rapid incorporation of a gene onto indication-based panel tests after the initial report of the gene's role in disease, without necessarily the accumulation of substantial corroborating evidence.

Multi-gene panel tests have clear advantages for diagnosis of conditions with significant genetic heterogeneity. At this point, however, minimum evidence thresholds to demonstrate a clinically valid gene-disease association have not been established. Panel tests may therefore include genes with a wide range of evidence. Given the sheer number of genes on some panel tests, ordering clinicians may have varying degrees of familiarity with any given gene and the evidence supporting its role as causative for a particular symptom or disease.

International efforts such as those by the Clinical Genome Resource (ClinGen) ${ }^{[2]}$, the Transforming Genetic Medicine Initiative ${ }^{[3]}$, and the Genomics England PanelApp ${ }^{[4]}$ aim to provide insight into the strength of evidence for gene-disease relationships. The process by which decisions are made by laboratorians to include genes on indication-based panel tests is likely impacted by multiple factors beyond simply reviewing the gene-disease evidence, however, and has not been previously described in the literature. This study aimed to investigate the potential relationship between the strength of evidence for a gene-disease association and inclusion of the gene on a targeted, indication-based gene panel test using the case of long QT syndrome (LQTS) and 15 of the genes associated with it. Further, we explored factors influencing laboratory decisions about the inclusion or exclusion of genes on a targeted, indication-based panel.

\section{LQTS}

LQTS is an inherited cardiac electrophysiological disorder with an estimated prevalence of $1: 2,500{ }^{[5]}$. It is characterized by prolongation of the QTc interval, which causes the heart muscle to take longer to prepare for each beat and may lead to torsade de pointes (TdP), a ventricular tachycardia that can progress to ventricular fibrillation and sudden death ${ }^{[6]}$. Syncope is the most common impetus for clinical evaluation ${ }^{[5]}$. Alternatively, a prolonged QTc can remain clinically asymptomatic for an individual's entire life ${ }^{[7]}$. Cardiac events can occur at any age but are most common in children and adolescents, often with serious complications that frequently correlate with exercise, intense emotional states, or auditory stimuli ${ }^{[8,9]}$. Complicating the etiologic assessment is the fact that some exogenous factors (e.g., pharmacologic agents) can induce a prolonged QTc interval, perhaps in combination with genetic risk factors ${ }^{[10]}$.

LQTS is divided into different types based on the underlying genetic cause as well as whether the long QT phenotype is isolated or part of a broader, multisystem syndrome. For the purposes of this study, we focused on genes associated with the nonsyndromic, autosomal dominant forms of LQTS.

Ideally, genetic testing for LQTS is initiated in a symptomatic individual. If a pathogenic variant in a LQTSassociated gene is identified, family members can have specific testing of that variant to learn if they have the 
condition. The diagnosis of LQTS can, thus, be made solely on identification of a pathogenic variant in an LQTS gene in the absence of symptoms ${ }^{[11]}$. Because sudden cardiac death is a possible presentation of LQTS, an affected individual may not be available for genetic testing. This can lead to the situation in which a presumed pathogenic variant is identified only in asymptomatic individuals. Asymptomatic individuals with pathogenic variants in LQTS-associated genes may also be identified incidentally when undergoing exome or genome-scale genetic tests for other clinical indications.

For individuals with a "molecular" diagnosis of LQTS based solely on a reported pathogenic variant, it is not possible to predict if or when symptoms may present. Penetrance, or the chance that an individual with LQTS will experience clinical symptoms in their lifetime, is incomplete for all LQTS genes ${ }^{[12]}$. Furthermore, it is not possible to fully adjudicate a suspected molecular diagnosis of LQTS given that a normal ECG cannot exclude the possibility of future symptoms ${ }^{[13]}$. Because of the risk for sudden, serious cardiac events, these patients must be followed for the possibility of LQTS symptoms. Recommended treatment includes beta blocker therapy and lifestyle modifications to avoid high intensity activity, emotional stressors, loud noises, and QT-prolonging drugs ${ }^{[5]}$. The European Society for Cardiology recommends that beta-blockers be considered in asymptomatic carriers of a causative LQTS mutation who have normal QT interval ${ }^{[14]}$. The resulting impact of living with risk to develop LQTS symptoms is associated with significantly reduced quality of life and higher parental anxiety ${ }^{[15,16]}$.

Given the health and psychological burden of living "at-risk" for LQTS, accurate interpretation of panel test results is crucial to ensure a correct molecular diagnosis. Interpretation requires both that the variant be pathogenic and the gene be causative of LQTS. Reaching agreement on the interpretation of pathogenicity for a variant has been shown to be difficult among laboratories. Van Driest et al ${ }^{[13]}$ demonstrated discordance in the interpretation of variants in two of the most well-evidenced LQTS genes, KCNH2 and SCN5A. For genes with limited evidence of a causal relationship, interpretation is further complicated by whether any variant can be considered pathogenic. Reporting results in genes that are not clinically valid can cause irreparable harm, leading to unnecessary worry and repeated cardiac workup for some and incorrect reassurance for others. Given that early diagnosis and treatment can be life-saving, clinicians and laboratories must balance the desire to increase test sensitivity with the ability to conclusively interpret the identified variants and implement appropriate surveillance and preventive measures.

\section{METHODS}

\section{Literature search and gene evidence curation}

OMIM was queried to identify the genes associated with hereditary LQTS and references supporting the association between each gene and LQTS. A comprehensive PubMed query was conducted to identify relevant information for the curation of each gene as described below. PubMed search syntax included the gene symbol and disease name (e.g., LQTS1, "KCNQ1 AND Long QT Syndrome").

The gene evidence curated from the literature search included: (1) the year each gene was first asserted to be associated with LQTS; (2) the number of clinical cases associated with each gene; (3) the size and number of affected families that exhibit segregation of the phenotype with the genotype; and (4) the robustness of the associated functional data [Table 1]. Cases were included in the total count if the patient had a variant plus either a prolonged QTc on an EKG or clinical symptoms. Segregation data was considered strong if a gene variant was found in the majority of symptomatic or EKG positive members of at least one large family ( 3 or more generations) without being found in asymptomatic or EKG negative members. Segregation data was considered moderate if the same criteria were met in small families (1 or 2 generations). The robustness of functional data was determined based on the presence of multiple lines of supportive experiments that demonstrated the role for that particular gene in the LQTS disease phenotype. Examples of functional data considered to be supportive of a gene-disease correlation include gene expression analysis that demonstrates the 
Table 1. Key information elucidated from the literature search and stakeholder interviews

\begin{tabular}{|c|c|c|c|c|c|c|c|c|c|}
\hline $\begin{array}{l}\text { LQT gene } \\
\text { symbol }\end{array}$ & $\begin{array}{l}\text { Associated } \\
\text { LQT subtype }\end{array}$ & $\begin{array}{c}\text { OMIM } \\
\text { phenotype } \\
\text { number }\end{array}$ & $\begin{array}{l}\text { Year } \\
\text { of first } \\
\text { clinical } \\
\text { case }\end{array}$ & $\begin{array}{l}\text { Number } \\
\text { of report- } \\
\text { ed cases }\end{array}$ & $\begin{array}{l}\text { Segre- } \\
\text { gation } \\
\text { data }\end{array}$ & $\begin{array}{l}\text { Func- } \\
\text { tional } \\
\text { data }\end{array}$ & $\begin{array}{l}\text { Genomics } \\
\text { England } \\
\text { PanelApp }\end{array}$ & $\begin{array}{c}\text { Year gene } \\
\text { was first } \\
\text { found on a } \\
\text { LQTS panel }\end{array}$ & $\begin{array}{c}\text { Years from } \\
\text { discovery to } \\
\text { placement } \\
\text { on panel }\end{array}$ \\
\hline KCNQ1 & LQTS 1 & 192500 & 1996 & $>100$ & ++ & ++ & Green & 2004 & 8 \\
\hline KCNH2 & LQTS 2 & 613688 & 1995 & $>100$ & ++ & ++ & Green & 2004 & 9 \\
\hline SCN5A & LQTS 3 & 603830 & 1995 & $>100$ & ++ & ++ & Green & 2004 & 9 \\
\hline ANK2 & LQTS 4 & 600919 & 2003 & 57 & ++ & ++ & Green & 2008 & 5 \\
\hline KCNE1 & LQTS 5 & 613695 & 1997 & 25 & ++ & ++ & Green & 2004 & 7 \\
\hline KCNE2 & LQTS 6 & 613693 & 1999 & 16 & + & ++ & Green & 2004 & 5 \\
\hline KCNJ2 & LQTS 7 & 170390 & 2001 & 54 & + & ++ & Green & 2008 & 7 \\
\hline CACNATC & LQTS 8 & 601005 & 2004 & 52 & ++ & ++ & Green & 2008 & 4 \\
\hline CAV3 & LQTS 9 & 611818 & 2006 & $4^{[17,18]}$ & - & ++ & Red & 2008 & 2 \\
\hline$S C N 4 B$ & LQTS 10 & 611819 & 2007 & $4^{[19]}$ & + & + & Red & 2008 & 1 \\
\hline AKAPQ & LQTS 11 & 611820 & 2007 & $3^{[20,21]}$ & - & ++ & Red & 2009 & 2 \\
\hline SNTA1 & LQTS 12 & 612955 & 2008 & 9 & + & + & Green & 2009 & 1 \\
\hline KCNJ5 & LQTS 13 & 613485 & 2010 & 8 & ++ & + & Green & 2010 & 0 \\
\hline CALM1 & LQTS 14 & 616247 & 2013 & 10 & + & - & Red & * & * \\
\hline CALM2 & LQTS 15 & 616249 & 2013 & 10 & - & - & Red & * & * \\
\hline
\end{tabular}

*Not queried at the time of the interviews because CALM1 and CALM2 had not yet been asserted to cause LQTS. They are included here for comparison. GenomicsEngland PanelApp designations are included for comparison; ++: strong supporting segregation/functional data; +: moderate supporting segregation/functional data. -: lack of significant supporting segregation/functional data; Green: high evidence; Red: low evidence. Long QT syndrome genes accessed at: https://panelapp.genomicsengland.co.uk/panels/76/

gene is expressed in the target tissue, ion channel protein expression and functional assays, gene knock-out and rescue, animal models and, to a lesser degree, in silico predictions. Genes with numerous and multiple types of functional data were given the highest level of functional evidence. Comparatively, genes with fewer papers/experiments describing functional data from a narrower range of categories were given moderate or minimal levels of functional evidence. Animal models were weighted heavier than the other types of functional data. Gene evidence curation was done initially in November 2014 and last updated in January 2018.

\section{Stakeholder interviews}

Sixteen laboratories were identified via the Genetic Testing Registry (GTR) as candidates for the interview. The following filters were used to establish which laboratories met our criteria on the GTR website: Long QT Syndrome clinical test, CLIA certified, and located in the United States. After contacting a representative of each lab using the contact information in the GTR, seven labs were disqualified for having a suspended panel (one laboratory) or having only broader tests that focused on whole exome sequencing, whole mitochondrial sequencing, general cardiology, cardiomyopathies, or caveolinopathies. Representatives from nine remaining laboratories agreed to participate and identified a key informant from the laboratory to participate in the telephone interviews. Key informants described themselves as genetic counselors or laboratory directors. Laboratory and key informant identities were kept confidential using a numerical code. The interviews took place during fall/winter 2014-2015.

The following questions were presented to interview participants in a semi-structured, open ended format:

(1) When did your laboratory first offer testing for LQTS? What genes were included and why?

(2) How has your offering changed since its inception? Why?

(3) Describe factors that you feel may have influenced the decision to add a new gene to the test;

(4) Going forward, what do you think would impact the decision to add or remove genes from your LQTS test?

All interviews were conducted by the same researcher, LB, to ensure consistency. Responses were recorded through detailed notation. 


\section{RESULTS}

\section{Literature search and gene curation}

Results from the literature search and gene evidence curation are displayed in Table 1. The first LQTS genes to be identified molecularly and associated with the condition were $\mathrm{KNCH} 2$ and SCN5A in 1995 . Notably, loci for many of the LQTS subtypes were defined by linkage, often preceding the discovery of a putative disease-associated gene; thus the subtype nomenclature does not necessarily correlate directly with the year of the first "clinical case." The rate of discovery of LQTS genes has remained fairly steady with about one new gene-disease association asserted every 1-2 years on average. KCNQ1 and SCN5A associated LQTS have significantly more known cases than the other LQTS genes with greater than 100 reported cases each in the literature. In comparison, $C A V 3, S C N 4 B, A K A P 9$, $S N T A 1$ and $K C N J 5$ have fewer than 10 reported LQTS cases each.

Whereas the rate of discovery has not changed, the time from assertion to testing has decreased. It took between 4-9 years for genes discovered from 1995-2004 to be incorporated on a multi-gene panel, whereas genes with reported associations after 2006 required 2 years or fewer to be incorporated on a panel.

Regarding segregation of variants with a LQTS phenotype, KCNQ1, KCNH2, SCN5A, ANK2, KCNE1, CAC$N A 1 C$, and $K C N J 5$ have the strongest support with gene variants segregating with disease in at least one large family. KCNE2, KCNJ2, $S C N 4 B, S N T A 1$, and CALM1 have a lesser amount of segregation evidence in smaller families. No segregation data was identified for $C A V 3, A K A P 9$, and $C A L M 2$. Regarding functional data, KCNQ1, KCNH2, SCN5A, ANK2, KCNE1, KCNE2, KCNJ2, CACNA1C, CAV3, and AKAP9 have the highest level. SCN4B, SNTA1, and KCNJ5 have moderate associated functional data. CALM1 and CALM2 have minimal associated functional data.

\section{Stakeholder interviews}

The composition of each laboratory's LQTS panel test over time is presented in Table 2. At the time of the interviews, seven of nine laboratories tested at least for the three genes that constitute the majority of pathogenic variants in LQTS patients $(K C N Q 1, K C N H 2 \text { and } S C N 5 A)^{[22]}$. The two outliers, lab 6 and lab 9, had more restricted test offerings that reflected specific laboratory interests, small laboratory size, and the limitations of Sanger sequencing. Both labs expanded their panels after implementing massively parallel sequencing (MPS). In general, multiple informants noted that advancing from Sanger sequencing to MPS was a major factor in the ability to expand gene panels due to increased speed of gene testing and decreased cost of test development. Lab 5 initially offered only sequencing of SCN5A due to gene patents. When these were dissolved, adding $K C N Q 1$ and $\mathrm{KCNH} 2$ was prioritized to achieve the highest yield possible balancing development costs at that time using Sanger sequencing, which was quoted at \$500-10,000 per gene. Lab 5 later expanded its panel after implementing MPS technology to incorporate additional LQTS genes.

Laboratories 1, 3, 4, and 7 did not join the market until 2013 or later. By this time, MPS technology was standard and 13 genes had already been identified which may explain why their initial test included all or nearly all genes. Notably, intellectual property played a significant role in panel development prior to 2008 when one lab held most of the LQTS gene patents ${ }^{[23]}$. In 2008 a second lab acquired licensing rights to multiple LQTS genes and shortly thereafter the available market tests were expanded from 5 genes to 10 genes. This is reflected in Table 1.

In addressing what genes to include on a panel, many informants referred to the balance between offering a clinically valid yet competitive test in the current genetic test market. Several informants mentioned the importance of general evidence criteria for a gene to be placed on a panel. In addition to scientific support, clinician/customer request and competitive pressures from other laboratories were independently mentioned as factors by some. Most also noted that these factors would likely continue to have influence in deciding which genes to add. 
Table 2. LQTS panel offered by each lab at initiation and at the time of the interviews

\begin{tabular}{|c|c|c|c|c|c|c|c|c|c|c|}
\hline & Lab 1 & Lab 2 & Lab 3 & Lab 4 & Lab 5 & Lab 6 & Lab 7 & Lab 8 & Lab 9 & $\begin{array}{l}\text { Number of } \\
\text { labs that test } \\
\text { for each gene }\end{array}$ \\
\hline KCNQ1 & $\bullet$ & - & - & $\bullet$ & 0 & & $\bullet$ & $\bullet$ & & 7 \\
\hline $\mathrm{KCNH} 2$ & - & - & $\bullet$ & $\bullet$ & o & & - & • & & 7 \\
\hline SCN5A & - & - & - & - & - & & $\bullet$ & - & & 7 \\
\hline ANK2 & $\bullet$ & $O^{*}$ & $\bullet$ & $\bullet$ & & & - & $\bullet$ & & 6 \\
\hline KCNE1 & - & $\bullet$ & - & $\bullet$ & & & - & $\bullet$ & & 6 \\
\hline KCNE2 & $\bullet$ & $\bullet$ & $\bullet$ & $\bullet$ & & & - & $\bullet$ & & 6 \\
\hline KCNJ2 & $\bullet$ & 0 & - & $\bullet$ & & $\bullet$ & $\bullet$ & $\bullet$ & & 7 \\
\hline CACNA1C & • & O & - & $\bullet$ & & & - & $\bullet$ & $\bullet$ & 7 \\
\hline CAV3 & • & 0 & $\bullet$ & - & & $\bullet$ & $\bullet$ & $\bullet$ & & 7 \\
\hline SCN4B & $\bullet$ & 0 & $\bullet$ & $\bullet$ & & & $\bullet$ & $\bullet$ & & 6 \\
\hline AKAP9 & - & 0 & - & • & & & • & 0 & & 6 \\
\hline SNTA1 & • & 0 & $\bullet$ & $\bullet$ & & & $\bullet$ & O & & 6 \\
\hline KCNJ5 & $\bullet$ & $0^{*}$ & $\bullet$ & & & & $\bullet$ & & & 4 \\
\hline Year gene added to test & 2013 & $\begin{array}{l}2004=\bullet, \\
2009=0, \\
2010=0^{*}\end{array}$ & 2013 & 2014 & $\begin{array}{l}2010=\bullet \\
2014=0\end{array}$ & 2010 & 2014 & $\begin{array}{l}2008=\bullet \\
2010=0\end{array}$ & 2011 & \\
\hline
\end{tabular}

-: Genes on initial test; $\mathrm{O}$ : genes added later; $\bullet+0$ : test offered at the time of the interviews; ${ }^{\star} \mathrm{CALM} 1 \mathrm{and} \mathrm{CALM} 2$ are not included in this table since they were not yet asserted to cause LQTS at the time of the interviews

Overall, the level of supportive evidence for each gene based on the literature searches did not correlate with the representation of the genes on panel tests as genes having less supportive evidence (CAV3, $S C N 4 B$, $A K A P 9, S N T A 1$, and $K C N J 5)$ were on a similar number of panels as genes with significant supporting evidence (KCNQ1, KCNH2, SCN5A, KCNE1, KCNE2, KCNJ2, ANK2, and CACNA1C). Comments made by informants point to competitive factors being one reason for this trend (e.g., "Now there's a genes arms race between labs. Everyone is trying to have a larger panel." "The laboratorians putting panels together are lowering their thresholds for what genes to add to compete with other labs.").

Notably, no one described criteria for what would be necessary to remove a gene. In fact, no informant could remember a time when a gene was removed from a LQTS panel. As one said, "It is easy to get one on, hard to get one off our list".

Though KCNJ5 and SNTA1 were considered to have less supportive evidence at the time of our interviews, their "green" assertions by Genomics England PanelApp are up to date and may indicate an increase in validity since our interviews were conducted.

\section{DISCUSSION}

Technological advances like MPS have led to continued discovery of potential disease-associated genes. At the same time, this technology allows genes to be added to panel tests at a fraction of the cost of older methods of testing, promoting the rapid addition of genes to clinical tests even if evidence for their clinical validity is limited. Our examination of the evolution of clinical testing for LQTS demonstrates this trend, though other factors such as clinician request, lab size, lab focus, and competitive pressures also play a role in what genes are added to panels. This study has the limitation that it was conducted over four years ago and informants were not re-interviewed; however, the literature search and gene curation were updated prior to publication.

Findings from this analysis indicate that the rate of discovery of genes asserted to be involved in LQTS has remained fairly steady over time though the time from gene discovery to test has decreased substantially, 
notably since 2006. Interestingly, within the 2006-2010 timeframe, many gene patents for LQTS genes were being reversed, and new laboratories began offering panel tests for LQTS. Whether this relationship is causal or coincidental cannot be determined from our investigation. However, new laboratories may have been eager to quickly become competitive, adding genes with less supporting evidence, thereby creating panels that included genes that are lower yielding or with more uncertainty with respect to natural history than initially expected.

In terms of the relationship of the evidence base to time to testing, it is not surprising that the first eight genes associated with LQTS have more reported cases than the last seven to be asserted. The first genedisease associations were likely those that account for the majority of cases and thus more amenable to gene discovery. Overall, the earlier genes also had a higher level of segregation data and functional data with a few key exceptions. $C A V 3$ and $A K A P 9$ were associated with disease before SNTA1, KCNJ5, and CALM1 but have less segregation data. However, $C A V 3$ and $A K A P 9$ have a higher amount of functional and experimental evidence compared to other genes discovered since 2006. This may explain why they have remained on LQTS panels despite a low number of total cases and no segregation data. It was also noted that one lab, lab 4, includes AKAP9 but not KCNJ5 on its panels even though KCNJ5 has more published clinical cases. This may reflect that AKAP9 was associated with LQTS > 10 years ago, and initially expected to be a major contributing gene based on significant gene function studies. It may also reflect the trend not to remove genes from panel tests once they are added. To date, only $\sim 3$ cases are attributed to AKAP9 in clinical literature and databases.

Clinical testing for a gene with limited evidence for disease association creates obstacles for interpretation. There is a need for uniform assessment of the validity of gene-disease associations, especially since our study found no correlation between gene-specific evidence and placement on panels. Genetic disorders with decreased penetrance and unclear genotype-phenotype correlations are in particular need of more knowledge.

Developing and disseminating these assessments is paramount and has become the focus of several international efforts. A trusted source documenting clinical validity of gene-disease associations may help combat competitive pressure to have the largest panel in favor of having a well-curated, clinically valid panel. ClinGen is an NIH-funded organization that aims to create an authoritative central resource to define the clinical relevance of genes and variants for use in precision medicine and research ${ }^{[2]}$. The ClinGen framework includes case-level, case-control, and supporting experimental data to allow curators and disease experts to assess of the validity of a gene-disease relationship and assign a clinical validity classification ${ }^{[24]}$. The classifications are publically available at: https://www.clinicalgenome.org/curation-activities/gene-disease-validity/ results/.

At the time of writing, a ClinGen Gene Curation Expert Panel for Long QT Syndrome had begun to curate and assess the clinical validity of LQTS genes. (https://www.clinicalgenome.org/working-groups/clinicaldomain/cardiovascular-clinical-domain-working-group/long-qt-gene-curation-expert-panel/).

Similarly, Genomics England PanelApp is a public database that serves to create virtual gene panels that can be reviewed by experts around the world with the goal of establishing a final "green" panel for every disorder to simplify development of appropriate indication-based gene panel tests and thereby interpretation. PanelApp has reviewed LQTS genes and published their recommendation regarding placement of genes on an indication-based panel at: https://panelapp.genomicsengland.co.uk/panels/76/. At this time, however, no groups or regulatory bodies make specific recommendations for labs regarding what level of clinical validity evidence should be required for inclusion on a clinical test ${ }^{[2]}$.

MPS technology enables options to attempt balance between the generation of clinical case evidence, the ability to rapidly add clinically valid genes, and ensuring that clinically available testing is based on sound 
evidence. One option applied by some laboratories is to separate genes on indication-based panels into a "clinical" panel and a masked "research" list of genes. The clinical panel genes are those that demonstrate strong evidence for clinical validity and would be analyzed and reported. Research genes would include those with minimal evidence for clinical validity. These research genes could be analyzed with patient consent, but not reported. Once a research gene gains enough evidence to be clearly associated with disease, it could be moved to the clinical gene list. Some laboratories that have included genes of various levels of evidence on clinical test offerings have attempted to differentiate genes that have only preliminary evidence of association with the panel test indication, allowing clinicians to opt-in to analysis of those genes or not.

In advocating for these efforts, there must be a distinction between clinical care and clinical research. The precipitous drop in time between discovery and market presents a complex scenario in which robust replication studies may be lacking. On one hand, many diseases are exceedingly rare, and waiting for large numbers of cases is not feasible. On the other hand, a gene could later be determined to have a lesser or no association with the particular disease. While identifying the underlying molecular diagnosis could provide guidance to patients and their treating clinicians, providing an erroneous diagnosis could lead to harms in over treatment (false positive) or failing to make the correct diagnosis (false negative). These difficulties of weighing the harms and benefits of rapid bench discovery to clinical market and increasing size and clinical scope of multi-gene panel tests have been a concern noted by investigators in a variety of diseases with genetic heterogeneity including cancers and vascular disease ${ }^{[26-28]}$.

In conclusion, our evaluation of the LQTS genes illustrates the nuanced relationship between published evidence supporting gene-disease associations and availability of clinical testing. Genetic tests are expanding, and laboratories may be resistant to remove genes from panels once they are added. Furthermore, once a genetic test result has been reported clinically, it may be very difficult to "withdraw" that result from the clinician and patient perspective, even if the gene-disease association is later called into question.

Thus, it is essential for genes on indication-based panels to be supported by appropriate levels of evidence to ensure good clinical care. We have presented the example of LQTS genes which represents generalizable themes across the clinical reality of genomic medicine and in particular for diseases with genetic heterogeneity. This work highlights the importance of and continual need for expert assessment of the clinical validity of gene-disease relationships such as those being conducted by the ClinGen consortium. Additional study is required to explore the ultimate impact of clinical validity information on the composition of clinical gene tests as well as their utilization by clinicians, coverage by health insurance policies, and impact on patients.

\section{DECLARATIONS}

\section{Acknowledgments}

We wish to thank Michael Adams, Debra Skinner, and Bradford Powell for their valuable comments and contributions to this paper.

\section{Authors' contributions}

Design: Boshe L, Berg JS, O’Daniel JM

Literature research: Boshe L

Data analysis: Boshe L, O’Daniel JM

Manuscript writing: Boshe L, Foreman AKM, Goldstein JL, Strande NT, Berg JS, O’Daniel JM

Manuscript editing: Boshe L, O’Daniel JM

\section{Availability of data and materials}

Data from the literature review can be made available on request. Key informant interview notes can be provided in aggregate themes to protect informant confidentiality and privacy. 


\section{Financial support and sponsorship}

None.

\section{Conflicts of interest}

The authors declared that there are no conflicts of interest.

\section{Ethical approval and consent to participate}

This study was approved as exempt, \#14-2303, by the institutional review board of the University of North Carolina- Chapel Hill.

\section{Consent for publication}

Not applicable.

\section{Copyright}

(C) The Author(s) 2018.

\section{REFERENCES}

1. Chong JX, Buckingham KJ, Jhangiani SN, Boehm C, Sobreira N, Smith JD, Harrell TM, McMillin MJ, Wiszniewsk W, Gambin T, Akdemir ZHC, Doheny K, Scott AF, Avramopoulos D, Chakravarti A, Hoover-Fong J, Mathews D, Witmer PD, Ling H, Hetrick K, Watkins L, Patterson KE, Reinier F, Blue E, Muzny D, Kircher M, Bilguvar K, López-Giráldez F, Sutton RV, Tabor HK, Leal SM, Gunel M, Mane S, Gibbs RA, Boerwinkle E, Hamosh A, Shendure J, Lupski JR, Lifton RP, Valle D, Nickerson DA, Bamshad MJ; Centers for Mendelian Genomics. The genetic basis of mendelian phenotypes: discoveries, challenges, and opportunities. Am J Hum Genet 2015;97:199-215.

2. Rehm HL, Berg JS, Brooks LD, Bustamante CD, Evans JP, Landrum MJ, Ledbetter DH, Maglott DR, Martin CL, Nussbaum RL, Plon SE, Ramos EM, Sherry ST, Watson MS; ClinGen. ClinGen - The Clinical Genome Resource. N Engl J Med 2015;372:2235-42.

3. Transforming Genetic Medicine Initiative (TGMI) online resource. GEMSTAR. Available from: http://www.thetgmi.org//gemstar/. [Last accessed on 24 Jun 2018]

4. Genomics England PanelApp online resource. Long QT syndrome (Version 1.5). Available from: https://panelapp.genomicsengland.co.uk/ panels/76/. [Last accessed 24 Jun 2018]

5. Shah SR, Ki P. Long QT syndrome: a comprehensive review of the literature and current evidence. Curr Probl Cardiol 2018;18:30051-3.

6. Amin AS, Arthur AMW. Genetic screening in acquired long QT syndrome? Caution: proceed carefully. Eur Heart J 2016;37:1465-8.

7. Rohatgi RK, Sugrue A, Bos JM, Cannon BC, Asirvatham SJ, Moir C, Owen HJ, Bos KM, Kruisselbrink T, Ackerman MJ. Contemporary outcomes in patients with LQTS. J Am Coll Cardiol 2017;70:453-62.

8. Moss AJ, Schwartz PJ, Crampton RS, Tzivoni D, Locati EH, MacCluer J, Hall WJ, Weitkamp L, Vincent GM, Garson A Jr., Robinson JL, Benhorin J, Choi S. The long QT syndrome. Prospective longitudinal study of 328 families. Circulation 1991;84:1136-44.

9. Fernández-Falgueras A, Sarquella-Brugada G, Brugada J, Brugada R, Campuzano O. Cardiac channelopathies and sudden death: recent clinical and genetic advances. Biology (Basel) 2017;6.pii:E7.

10. Itoh H, Crotti L, Aiba T, Spazzolini C, Denjoy I, Fressart V, Hayashi K, Nakajima T, Ohno S, Makiyama T, Wu J, Hasegawa K, Mastantuono E, Dagradi F, Pedrazzini M, Yamagishi M, Berthet M, Murakami Y, Shimizu W, Guicheney P, Schwartz PJ, Horie M. The genetics underlying acquired long QT syndrome: impact for genetic screening. Eur Heart J 2016;37:1456-64.

11. Priori SG, Wilde AA, Horie M, Cho Y, Behr ER, Berul C, Blom N, Brugada J, Chiang CE, Huikuri H, Kannankeril P, Krahn A, Leenhardt A, Moss A, Schwartz PJ, Shimizu W, Tomaselli G, Tracy C. Executive summary: HRS/EHRA/APHRS expert consensus statement on the diagnosis and management of patients with inherited primary arrhythmia syndromes. Heart Rhythm 2013;10:e85-108.

12. Giudicessi JR, Wilde AAM, Ackerman MJ. The genetic architecture of long QT syndrome: a critical reappraisal. Trends Cardiovasc Med 2018; doi: 10.1016/j.tcm.2018.03.003.

13. Van Driest SL, Wells QS, Stallings S, Bush WS, Gordon A, Nickerson DA, Kim JH, Crosslin DR, Jarvik GP, Carrell DS, Ralston JD, Larson EB, Bielinski SJ, Olson JE, Ye Z, Kullo IJ, Abul-Husn NS, Scott SA, Bottinger E, Almoguera B, Connolly J, Chiavacci R, Hakonarson H, Rasmussen-Torvik LJ, Pan V, Persell SD, Smith M, Chisholm RL, Kitchner TE, He MM, Brilliant MH, Wallace JR, Doheny KF, Shoemaker MB, Li R, Manolio TA, Callis TE, Macaya D, Williams MS, Carey D, Kapplinger JD, Ackerman MJ, Ritchie MD, Denny JC, Roden DM. Association of arrhythmia-related genetic variants with phenotypes documented in electronic medical records. JAMA 2016;315:47-57.

14. Priori SG, Blomström-Lundqvist C, Mazzanti A, Blom N, Borggrefe M, Camm J, Elliott PM, Fitzsimons D, Hatala R, Hindricks G, Kirchhof P, Kjeldsen K, Kuck KH, Hernandez-Madrid A, Nikolaou N, Norekvål TM, Spaulding C, Van Veldhuisen DJ. 2015 ESC guidelines for the management of patients with ventricular arrhythmias and the prevention of sudden cardiac death. Rev Esp Cardiol (Eng Ed) 2016; 69:176.

15. Czosek RJ, Kaltman JR, Cassedy AE, Shah MJ, Vetter VL, Tanel RE, Wernovksy, G, Wray J, Marino BS. Quality of life of pediatric patients with long QT syndrome. Am J Cardiol 2016;117:605-10.

16. Giuffre RM, Gupta S, Crawford SG, Leung AK. Fears and anxiety in children with long-QT syndrome compared to children with asthma. J Natl Med Assoc 2008;100:420-4. 
17. Vatta M, Ackerman MJ, Ye B, Makielski JC, Ughanze EE, Taylor EW, Tester DJ, Balijepalli RC, Foell JD, Li Z, Kamp TJ, Towbin JA. Mutant Caveolin-3 induces persistent late sodium current and is associated with long-QT syndrome. Circulation 2006;114:2104-12.

18. Ye B, Tester DJ, Vatta M, Makielski JC, Ackerman MJ. Molecular and functional characterization of novel CAV3-encoded caveolin-3 mutations in congenital long QT syndrome. Heart Rhythm 2006;3:S1.

19. Medeiros-Domingo A, Kaku T, Tester DJ, Iturralde-Torres P, Itty A, Ye B, Valdivia C, Ueda K, Canizales-Quinteros S, Tusié-Luna MT, Makielski JC, Ackerman MJ. SCN4B-encoded sodium channel 4 subunit in congenital long-QT syndrome. Circulation 2007;116:134-42.

20. Chen L, Marquardt ML, Tester DJ, Sampson KJ, Ackerman MJ, Kass RS. Mutation of an A-kinase-anchoring protein causes long-QT syndrome. Proc Natl Acad Sci USA 2007;104:20990-5.

21. Maltese PE, Orlova N, Krasikova E, Emelyanchik E, Cheremisina A, Kuscaeva A, Salmina A, Miotto R, Bonizzato A, Guerri G, Zuntini M, Nicoulina S, Bertelli M. Gene-targeted analysis of clinically diagnosed long QT Russian families. Int Heart J 2017;58:81-7.

22. Shimizu W. Clinical impact of genetic studies in lethal inherited cardiac arrhythmias. Circ J 2008;72:1926-36.

23. Angrist M, Chandrasekharan S, Heaney C, Cook-Deegan R. Impact of gene patents and licensing practices on access to genetic testing for long QT syndrome. Genet Med 2010;12:S111-54.

24. Strande NT, Riggs ER, Buchanan AH, Ceyhan-Birsoy O, DiStefano M, Dwight SS, Goldstein J, Ghosh R, Seifert BA, Sneddon TP, Wright MW, Milko LV, Cherry JM, Giovanni MA, Murray MF, O’Daniel JM, Ramos EM, Santani AB, Scott AF, Plon SE, Rehm HL, Martin CL, Berg JS. Evaluating the clinical validity of gene-disease associations: an evidence-based framework developed by the clinical genome resource. Am J Hum Genet 2017;100:895-906.

25. National human genome research institute (NHGRI) online resource. Regulation of Genetic Tests. Available from: www.genome. gov/10002335/regulation-of-genetic-tests/. [Last accessed on 25 Jun 2018]

26. Okur V, Chung WK. The impact of hereditary cancer gene panels on clinical care and lessons learned. Cold Spring Harb Mol Case Stud 2017;3: a002154.

27. Kurian AW, Li Y, Hamilton AS, Ward KC, Hawley ST, Morrow M, McLeod MC, Jagsi R, Katz SJ. Gaps in incorporating germline genetic testing into treatment decision-making for early-stage breast cancer. J Clin Oncol 2017;35:2232-9.

28. Wooderchak-Donahue W, VanSant-Webb C, Tvrdik T, Plant P, Lewis T, Stocks J, Raney JA, Meyers L, Berg A, Rope AF, Yetman AT, Bleyl SB, Mesley R, Bull DA, Collins RT, Ojeda MM, Roberts A, Lacro R, Woerner A, Stoler J, Bayrak-Toydemir P. Clinical utility of a next generation sequencing panel assay for Marfan and Marfan-like syndromes featuring aortopathy. Am J Med Genet A 2015;167A:1747-57. 